\title{
II. ORGANIZATION OF SYMPOSIA AND COLLOQUIA
}

\section{A. GENERAL}

One of the essential tasks of the Union is to encourage the circulation of ideas and the dissemination of scientific results by organizing meetings exceeding eventually the field of a Commission of the Union and requiring the co-operation of other scientific unions or organizations.

Such meetings bear the name of a symposium or a colloquium. Symposia are organized by Organizing Committees appointed by the Executive Committee of the IAU; colloquia are primarily organized by Commissions. Colloquia differ from symposia in that:

They are concerned with more precise topics.

They attract rather fewer participants and last a shorter time.

Smaller grants are made by the IAU for travel and organizational expenses.

Publication of the proceedings is generally arranged by the Commission, preferably in a non-commercial astronomical periodical.

There is no limit to the number of colloquia that may be organized, and formal approval only is required from the Executive Committee. Many of the meetings organized by Commissions during a General Assembly might be classed as colloquia.

Symposia, on the other hand, cover a broader field and have a larger attendance. The attendance at a symposium, however, is by invitation from the President of the Organizing Committee only.

The majority of symposia are held between the Assemblies. Thus they are a manifestation of the continuity of scientific activities of the Union. Only a limited number of symposia may take place in conjunction with a General Assembly and these should be predominantly astronomical in character. Symposia covering a broader field and requiring participation of nonastronomers, should be organized at times other than General Assemblies.

The choice of topics cannot be subject to any rules; even the tenor of the discussion may vary considerably from one symposium to another. Only the Organizing Committee is entitled to decide on the most suitable method of discussion, on the detailed choice of subjects, on the programme, on the presentation of formal papers, and on practical problems such as languages, translations, recording of the discussions, organization of the secretariat, etc.

A certain trend is, however, emerging: a wide discussion based on a small number of introductory papers is generally preferred to the presentation of formal communications. The discussion is given a good starting point by the distribution to participants, before the symposium, of introductory papers or detailed bibliography, as the case may be. But again, the Executive Committee of the IAU wishes the Organizing Committee to feel entirely free to make its own arrangements.

The aim of a symposium cannot be attained without the publication of the proceedings. The Union, recognizing the prime importance of this point, has decided that the proceedings of symposia will be published by the Union itself. This ensures that all requirements of the Union are satisfied and that each symposium is a part of a uniform series. 
A register of astronomical meetings, with some international participation, is maintained by the IAU Administrative Office. The main purpose of this register is to facilitate the avoidance of inadvertent duplication of subjects and dates. All Members of the Union and all concerned with the organization of symposia, colloquia, and other scientific meetings, are requested to inform the Administrative Office of the arrangements of all such meetings, preferably at the earliest planning stage.

\section{B. ORGANIZATION OF SYMPOSIA OF THE IAU}

Any individual Member of the Union, or a Commission of the Union, is entitled to submit a proposal for a symposium. The Presidents of interested Commissions should be contacted in order that they may submit their opinions on the proposed topic of the symposium. The proposal for a symposium may be even more detailed. It can contain suggestions for the place, date, and programme of the symposium, as well as a preliminary list of members of the Organizing Committee.

Proposals should be addressed to the Assistant General Secretary who is, under the present arrangement, responsible for all matters concerning symposia other than those dealing with the publication of the proceedings. Copies of letters containing proposals, and of all consequent correspondence, should be sent, as a matter of routine, to the General Secretary, who is often called upon at short notice to provide information about symposia.

The Executive Committee, after having been informed of the proposal for a symposium, decides on its suitability, timeliness, etc., and, after consultation with the authors of the proposal, takes decisions on the approximate date and place, on the programme and on the financial provision. The Executive Committee also appoints the President and members of the Organizing Committee of the Symposium; changes in the preliminary proposals are sometimes necessary in order to ensure the international character and broad scientific coverage desirable in the Organizing Committees of symposia.

The President of the Organizing Committee then takes decisions on the following and informs the Assistant General Secretary accordingly:

About 6 or 8 months before the Symposium: exact date and place.

About 4 months before the Symposium:

(a) detailed programme;

(b) choice of participants;

(c) appointment of one of the members of the Organizing Committee as the Scientific Editor of the proceedings;

(d) provisions made for the local organization.

About 2 months before the Symposium:

proposals for the distribution of the IAU financial allocation.

\section{PARTICIPATION OF THE IAU IN JOINT SYMPOSIA}

The IAU is willing to participate in symposia, jointly with other Unions or Inter-Union Committees, either as a principal or a subsidiary participant.

As the principal participant, the IAU:

(a) originates the Symposium and, either alone or in consultation with other Unions, plans the main features such as scope of subject, place and date; 
(b) appoints an Organizing Committee and its President;

(c) invites the co-operation and participation of other Unions; such co-operation could include, depending on circumstances:

(i) discussions of the main features,

(ii) appointment of representatives on the Organizing Committee,

(iii) contribution towards the expenses of the Symposium,

(iv) the drawing up of a list of participants, a scientific programme, methods of presentation, etc., through the representatives on the Organizing Committee,

(v) discussion on the publication of the proceedings, together with all associated questions of free distribution, price, payments and subsidies;

(d) would normally expect the other Unions to make some contribution to the expenses of the Symposium;

(e) would normally arrange for publication of the proceedings as one of the IAU Symposium volumes, but would consult the other Unions as to their wish to have special copies or to contribute financially in return for the volume being included in their series.

As a subsidiary participant, the IAU would:

(a) accept the leading role of the principal participant in all relevant matters;

(b) wish to appoint representatives on the Organizing Committee, to be consulted on all important questions, and to be kept informed of decisions on other matters;

(c) in principle, contribute towards the expenses;

(d) wish to be consulted in regard to the publication of the proceedings, especially in regard to the distribution of free copies to participants.

The IAU would like to suggest that symposia organized jointly by one or more Unions should always be announced in the following terms:

Organized by the IAU in co-operation with IUGG and COSPAR (e.g.) or

Organized by IUHPS (e.g.) in co-operation with the IAU.

\section{FINANCIAL PROBLEMS}

The Executive Committee of the IAU allocates to each symposium a limited sum which is meant as a "catalyzer" to encourage other international or national organizations to subsidize 'the Symposium. The IAU grant is used exclusively to cover travel expenses of the participants and to meet some of the expenses of the secretariat of the Symposium if necessary. Other expenses are generally covered as follows:

Subsistence expenses of the participants: by the participants themselves or by grants from their Governments or home institutions.

Travel expenses of the participants: partly by grants from the IAU fund, partly by grants from other organizations.

Expenses of the secretariat of the Symposium: partly from the IAU funds, partly by organizations in the host country or by home institutions of the members of the Organizing Committee.

Local organization (receptions, social events, excursions): by the host municipality, country or institute.

Publication of the proceedings: by the IAU. 
The President of the Organizing Committee asks each invited participant to obtain, if possible, financial aid through his home institute or country. A reference may be made in the letter to the rather limited sum that has been made available by the IAU for grants to participants.

After the President of the Organizing Committee has established what financial support is available to participants from other sources, he decides on the distribution of the IAU funds. Only in exceptional cases, may a participant receive a sum in excess of his travel expenses. The IAU will inform each President about an additional sum which can be used in case of need. It is recommended to keep this sum in reserve as long as possible in order to be able to face eventual emergency situations (a new participant, a last moment failure to obtain financial help, etc.).

\section{E. LOCAL ORGANIZATION}

As soon as one of the members of the Organizing Committee is put in charge of the local organization, he appoints a Local Committee and informs the President of the Organizing Committee about the composition of the Local Committee.

The Local Committee takes care of the smooth running of the Symposium. It does not receive any financial help from the IAU, the necessary expenses being covered by local funds or by contributions from the participants.

A member of the Local Committee can be made responsible for each of the tasks which have to be attended to. These appointments are made by the Chairman of the Local Committee. The requirements of local organization are generally as follows:

I. Meeting rooms suitable for the expected number of participants should be located and reserved.

2. Arrangements should be made to mimeograph and distribute papers presented by the participants, if desirable.

3. Sufficient secretarial and technical assistance should be made available for typing and duplicating, and for operating tape recorders, microphones, projection equipment, etc.

4. A record of the discussions must be kept. Two ways to do this have been found convenient at several symposia. If an exact record is desirable, a tape recorder is the best solution. It is, however, a difficult task for the scientific editor to restrict the recording of the discussion to the essentials. Another possibility is to hand to each speaker, immediately after he has delivered his contribution, a sheet of paper on which he is requested to write out his remark. Thus some editing is already done by the speakers themselves. In any case, it is desirable that all speakers should receive typed records of the discussions for checking before the end of the symposium.

5. Each participant should be met at the airport or railway station or should be in possession of sufficient information to find his own way.

6. Hotel rooms should be booked according to the wishes of the participants, preferably close to the meeting place and in a reasonable price range.

7. Receptions and excursions can be organized during the free periods of the Symposium, and possibly just before or after the Symposium. A ladies programme is a welcome courtesy.

8. Each participant should receive the following information sufficiently in advance, say, two months before the symposium:

(a) The name of his hotel and directions for finding it on arrival;

(b) directions for getting from his hotel to the meeting place;

(c) the price of his hotel, of the excursions and of other social events (unless covered by local organizations); 
(d) the detailed programme of the Symposium;

(e) a list of participants with their home addresses, as well as their addresses during the Symposium;

$(f)$ any other documents which the President of the Organizing Committee may consider useful.

\section{F. PUBLICATION}

The Executive Committee of the IAU is much concerned over the increasing practice of publishing essentially the same astronomical papers in several places. It calls upon all Members of the Union, the authors of all scientific papers, the editors of proceedings of symposia, colloquia, and other meetings, to avoid this duplication of effort. This is essential, not merely for reasons of economy, but primarily to keep to a minimum the increasing amount of astronomical literature.

Symposia should be planned from the beginning with this brevity in mind, and all participants should be informed at an early stage. Scientific editors should be prepared to omit, or to reduce the length of, contributed papers, where this can be done without loss of original material of scientific value. The General Secretary will provide general guidance in this matter and is authorized to state specific limits in particular cases.

Where material has already been published, or has been submitted for publication, it should be covered in the proceedings by a brief summary, coupled with a reference to the original source; detailed theoretical derivations, lists of observations and tabular data, diagrams and photographs, should never be repeated. Some repetition, however, is permissible in review papers.

The Scientific Editor of the Symposium is appointed by the Union from among the members of the Organizing Committee following a proposal by its President. His main tasks are:

(a) To inform the participants in ample time in what general form their contributions should be submitted.

(b) To inform participants that the final versions of their contributions should be available at the end of the Symposium or shortly thereafter.

(c) To ensure that adequate records of the discussions during the Symposium are being kept and to present the records to the contributors for inspection.

(d) To put the manuscripts and records of discussions into a homogeneous form (names, abbreviations, transliteration, references, etc.) corresponding to the requirements of Chapters $\mathrm{I}(a)$ and $\mathrm{I}(b)$, Part 2 , of this Handbook (see pages 55 to 127 ).

(e) To avoid any duplication of material and to reduce the length of papers and discussions with regard to the desirable brevity.

(f) To ensure that the edited manuscript is in the hands of the General Secretary of the Union not later than two months after the Symposium.

In order to obtain a presentation that will indicate that the volumes of IAU Symposia form a series, the Union requests that the Scientific Editors adhere to the following recommendations:

Title page. The title page should include explicitly, above the title of the Symposium and the date on which it was held, the words "IAU Symposium no. ...", followed, where appropriate, by the words "Organized by the IAU in co-operation with. .." in which the list of organizations is limited to the Scientific Unions, the Scientific Committees (such as COSPAR), Inter-Union Commissions of the ICSU (such as IUCAF). The participation of UNESCO will be acknowledged by the following wording: "Published for the International Council of Scientific Unions with the financial assistance of UNESCO”. 


\section{List of Contents.}

Introduction. The Introduction, by the President of the Organizing Committee for the Sympnsium, should specifically mention the various aspects of the organization of the Symposium, the membership of the Organizing Committee, the place and date, the list of participants, the support of the IAU and other Unions, etc., as well as an appreciation of the work of the local committee and of the assistance given by local organizations. Contributions by UNESCO, other scientific organizations, national or governmental organizations should also be recognized in the Introduction.

Proceedings of the Symposium. The proceedings will normally contain the texts of the bibliographic reports, of the original contributions, and of the reports (long or short as the case may be) of the discussions.

Alphabetical Index of names and subjects, if practicable.

The sub-editing and printing is dealt with by the Union. The galley-proofs are sent to the authors; the second proofs are read by the IAU Secretariat or by the Scientific Editor. It is expected to issue the volume in about eight months after the Symposium.

All Members of the Union are entitled to purchase copies of the proceedings of symposia at reduced prices, as indicated, for past symposia, pages $43-44$ of this volume, and for current and future symposia in the IAU Information Bulletins. 